\title{
Integração e inserção de calouros em Educação Física em uma Instituição Federal de Ensino Superior: Experiências da Semana de Recepção de Calouros 2020
}

\author{
Integration and insertion of freshmen in Physical Education in a Federal Institution of Higher
}

Education: Experiences of the 2020 Freshmen Reception Week 2020

Integración e inserción de estudiantes de primer año en Educación Física en una Institución

Federal de Educación Superior: Experiencias de la Semana de Recepción de Estudiantes de primer año 2020

\author{
Alini Silva Peixoto \\ ORCID: https://orcid.org/0000-0001-8570-6341 \\ Universidade Federal do Mato Grosso do Sul, Brasil \\ E-mail: alinipeixoto@hotmaill.com \\ Junior Vagner Pereira da Silva \\ ORCID: https://orcid.org/0000-0002-4098-9664 \\ Universidade Federal do Mato Grosso do Sul, Brasil \\ E-mail: jr_lazer@yahoo.com.br
}

\begin{abstract}
Resumo
O manuscrito objetiva relatar e descrever a "Semana de Recepção de Calouros" de um curso de Educação Física. Especificamente, busca apresentar as ações desenvolvidas e os resultados alcançados. Trata-se de um estudo descrito, do tipo relato de experiência, de ação organizada pelo Programa de Educação Tutorial na Universidade Federal de Mato Grosso do Sul, em 2020. Realizada em cinco dias, participaram discentes (ingressantes e veteranos), professores e servidores administrativos. Dispôs do acolhimento (boas vindas, explicação do "Trote Solidário - Arrecadação de Alimentos e roupas", apresentação do cronograma e dos espaços da instituição); palestra acadêmica-científicapedagógica sobre a formação de licenciados e bacharéis e o campo de atuação profissional; apresentação do coordenador, professores, servidores administrativos, programas institucionais vinculados ao curso - Programa de Educação Tutorial, Programa de Iniciação à Docência, Programa de Iniciação Científica, Programa Segundo Tempo Universitário -, projetos, grupos de estudos e entidades representantes discentes (Centro Acadêmico de Educação Física e Associação Atlética Acadêmica de Educação Física) e atividades lúdicas/esportivas (Torneio de Futsal, Gincana e práticas esportivas), que contaram com a participação de 29 (17/02), 34 (18/02 e 20/02) e 19 (21/02) calouros e 41 (17/02), 27 (18/02), $7(20 / 02)$ e 16 (21/02) veteranos. Conclui-se que a proposta promoveu o acolhimento dos ingressantes de forma respeitosa e informativa e os integrou aos veteranos, docentes e servidores administrativos, assim como promoveu acesso informativo aos tipos de formação e atuação profissional, projetos, programas, entidades representativas e vivências possíveis de desfrutarem na Cidade Universitária, embora ajustes às próximas edições se fazem necessários.
\end{abstract}

Palavras-chave: Ensino Superior; Calouros; Recepção; Lúdico.

\begin{abstract}
The manuscript aims to report and describe the "Freshman Reception Week" of a Physical Education course. Specifically, it seeks to present the actions developed and the results achieved. This is a described study, of the experience report type, of an action organized by the Tutorial Education Program at the Federal University of Mato Grosso do Sul, in 2020. Carried out in five days, students (newcomers and veterans), teachers and civil servants participated. administrative. Provided the reception (welcome, explanation of the "Trote Solidarity - Collection of food and clothes", presentation of the schedule and spaces of the institution); academic-scientific-pedagogical lecture on the training of graduates and bachelors and the field of professional activity; presentation of the coordinator, teachers, administrative staff, institutional programs linked to the course - Tutorial Education Program, Teaching Initiation Program, Scientific Initiation Program, Second Term University Program -, projects, study groups and student representative entities (Academic Center of Physical Education and Academic Athletic Association of Physical Education) and recreational/sporting activities (Futsal Tournament, Gymkhana and sports), which counted with the participation of 29 (2/17), 34 (2/18 and 2/20) and 19 (2/21) freshmen and 41 (2/17), 27 (2/18), $7(2 / 20)$ and $16(2 / 21)$ veterans. It is concluded that the proposal promoted the reception of newcomers in a respectful and informative manner and integrated them with veterans, teachers and administrative staff, as well as promoting
\end{abstract}


informational access to types of training and professional performance, projects, programs, representative entities and possible experiences of enjoy at Cidade Universitária, although adjustments to future editions are necessary.

Keywords: Higher Education; Freshmen; Reception; Ludic.

\section{Resumen}

El manuscrito tiene como objetivo informar y describir la "Semana de Recepción para Estudiantes de primer año" de un curso de Educación Física. En concreto, busca dar a conocer las acciones desarrolladas y los resultados alcanzados. Se trata de un estudio descrito, del tipo relato de experiencia, de una acción organizada por el Programa de Educación Tutorial de la Universidad Federal de Mato Grosso do Sul, en 2020. Realizado en cinco días, estudiantes (recién llegados y veteranos), docentes y Participaron criados administrativos. Se brindó la recepción (bienvenida, explicación del "Trote Solidario - Recogida de alimentos y ropa", presentación del horario y espacios de la institución); charla académico-científico-pedagógica sobre la formación de egresados y licenciados y el ámbito del desempeño profesional; presentación del coordinador, docentes, personal administrativo, programas institucionales vinculados al curso - Programa de Educación Tutorial, Programa de Iniciación Docente, Programa de Iniciación Científica, Programa Universitario de Segundo Término -, proyectos, grupos de estudio y entidades representativas de los estudiantes (Centro Académico de Educación Física y Asociación Atlética Académica de Educación Física) y actividades recreativas / deportivas (Torneo de Fútsal, Gymkhana y deportes), que contaron con la participación de 29 (2/17), $34(2 / 18$ y $2 / 20)$ y $19(2 / 21)$ estudiantes de primer año y $41(2 / 17), 27(2 / 18), 7(2 / 20)$ y $16(2 / 21)$ veteranos. Se concluye que la propuesta promovió la recepción de los recién llegados de manera respetuosa e informativa y los integró con veteranos, docentes y personal administrativo, además de promover el acceso informativo a tipos de formación y desempeño profesional, proyectos, programas, entidades representativas y posibles experiencias de disfrute en la Cidade Universitária, aunque son necesarios ajustes para futuras ediciones.

Palabras clave: Educación superior; Estudiantes de primer año; Recepción; Líduco.

\section{Introdução}

No Brasil, somente $32.7 \%$ da população na faixa etária de 18 a 24 anos dispõe de acesso ao Ensino Superior. Na faixa etária de 25 a 34 anos, os percentuais são ainda menores (19.7\%). Esse percentual é quase metade do alcançado por pessoas da mesma faixa etária em países que integram a Organização para a Cooperação e Desenvolvimento Econômico (Instituto Brasileiro de Geografia e Estatística, 2019), o que indica a discrepância na democratização do acesso ao Ensino Superior no país.

Aqueles que logram êxito nos diferentes processos de entrada as Universidades (vestibular, processo sequencial ou ENEM), enfrentam um processo de transição de rotinas, distribuição do tempo, conhecimento e reconhecimento de um novo espaço social (Universidade) a ser vivenciado. Neste processo de transição, de acordo com Kaji et al. (2021), profundas mudanças ocorrem no âmbito acadêmico, social, pessoal e familiar. Frente a nova realidade a qual os estudantes se deparam, Rios et al. (2021) ressaltam que os primeiros anos tornam-se vulneráveis ao estresse psicológico, exigindo que iniciativas sejam criadas de modo a diminuir os riscos de sua ocorrência.

Além dos fatores estressores inerentes a mudança de realidade e das novas obrigações estudantis, portanto, fatores estressantes inerentes ao processo de assimilação da nova realidade acadêmica, historicamente, as primeiras experiências ao acessar o Ensino Superior fizeram-se traumáticas, dado que a recepção ocorria por intermédio de trotes, pautados em "brincadeiras" que feriam a integridade, onde os veteranos se divertiam a partir de atitudes que subjugavam e inferiorizavam os calouros. Não raro, este tipo de comportamento estudantil, transformavam um momento que deveria ser repleto de felicidades, em ocasião hostil, pautada em humilhações, preconceitos, violência e medo, inclusive com casos de desistência da vida universitária e óbitos.

Zuin (2011) traça o percurso histórico das práticas 'tradicionais' de recepção universitária e afirma que a origem do trote se confunde com as da própria universidade, pontuando o primeiro registro de rituais do tipo na universidade de Paris em 1342 e que "as demarcações violentas das identidades dos calouros e de seus veteranos adquiriram cada vez mais força com o passar do tempo" (Zuin, 2011, p. 590), trazendo a descrição de como o calouro era caracterizado como animal irracional. Segundo Estanque (2017), atos violentos, característicos dessas práticas, também são identificados desde o início do século 
XVIII, na Universidade de Coimbra.

Akerman, Scalisa e Akerman (2015) que a violência em trotes universitários e a violência cometida contra ingressantes foi objeto de denúncias de violação de direitos humanos e resultaram na instauração de Comissão Parlamente de Investigação por parte da Assembleia Legislativa de São Paulo (ALESP) em 2015.

De modo a superar a perspectiva tradicional de recepção de calouros, nas últimas décadas, iniciativas em outro formato têm sido implantadas em Instituições de Ensino Superior (IES) como alternativa aos 'trotes' (Crivello Junior \& Bastos Filho, 2016), sendo recorrida como estratégia de atenção à saúde mental do estudante, de modo a diminuir o desconforto dos ingressantes frente ao desconhecido (Noto, et al., 2021).

A Universidade de São Paulo (USP) pode ser citada como um exemplo no uso dessa medida alternativa, vez que desde 1998 institucionalizou a "Semana de Recepção aos Calouros", com a substituição das aulas por atividades que estimulem valores cultivados no ambiente universitário, como "humanismo, solidariedade, universalismo, respeito ao indivíduo e excelência no aprendizado" (Crivello Junior \& Bastos Filho, 2016, p. 108). Em específico, a Faculdade de Medicina da USP (FMUSP), por meio do Programa Tutores, promoveu a organização de grupos de alunos orientados por um professor, de modo a contribuir na formação através de experiências e passou desde 2002 a participar da semana de recepção de calouros, o que se mostrou uma ação importante para ampliar a rede de suporte aos ingressantes dentro da instituição (Bellodi, 2004).

Diversas instituições promovem ações de recepção aos ingressantes, inclusive com exemplos em que a atividade relaciona-se com o Programa de Educação Tutorial (PET), programa federal criado em 1979. No Instituto Federal Goiano (IFGoiano), o PET Bio Urutaí planejou e executou a "Recepção Caulorosa" durante dois dias, com dinâmicas de apresentação dos alunos, dos professores e de áreas do campus relacionadas com o curso de Licenciatura em Ciências Biológicas e oportunidades existentes para os alunos de graduação (Lima, et al., 2014); na Universidade Federal de Goiás/Regional Jataí, o PET Enfermagem realizou um acolhimento e apresentação dos docentes, de atividades do curso e do sistema de gestão de atividades acadêmicas que os ingressantes precisam conhecer e acessar, em segundo momento os ingressantes realizaram o plantio de mudas de Ypê e conhecem o espaço físico da IES (Santos, et al., 2018); na Universidade Federal Rural do Semiárido (UFERSA), o PET Engenharia de Pesca realizou em dois dias atividades com de apresentação de docentes e programas e projetos além de uma mesa redonda com ex-alunos e uma visita aos laboratórios e uma gincana no segundo dia (Lopes, et al., 2020); na Universidade Federal do Maranhão (UFMA), o PET de Ciência da Computação organizou suas atividades em três dias, que incluíram a apresentação da IES e do curso com espaço para sanar dúvidas, dinâmicas de integração, tour pelos laboratórios e aulas de reforço em conteúdos matemáticos e lógicos (Pinto, et al., 2020); na Universidade Federal do Pará, o PET Farmácia desenvolve esse tipo de acolhida, de modo a possibilitar aos ingressantes o conhecimento do curso (Barros, Ramos, \& Dolabela, 2021).

Universitários que interagem social e academicamente desde o início do curso são mais propensos a desenvolverem crescimento intelectual e pessoal do que aqueles que não tiveram essa interação (Lopes, et al., 2020). Entre os diversos aspectos positivos da realização de uma recepção acolhedora, ressalta-se a aproximação harmoniosa entre o ingressante e os veteranos, a diminuição da evasão gerada por conflitos entre alunos, a relações de cooperação e de respeito entre alunos, professores e servidores (Costa, et al., 2017).

Compactuando do entendimento de que a Universidade deve figurar como espaço promotor de significados e pertencimento aos estudantes, logo, lugar, entende-se por necessário que o ritual de iniciação à vida universitária seja pautada em atividades que promovam o conhecimento da infraestrutura física da instituição, os recursos humanos (docentes e administrativos), projetos e programas disponíveis, instâncias de representações estudantis, como também que os ingressantes sejam social e afetivamente acolhidos por veteranos, professores e servidores, o que corrobora com a socialização desde o 
ingresso ao ensino superior.

No âmbito do curso de Educação Física da Universidade Federal de Mato Grosso do Sul, ação pautada no acolhimento, de modo a superar o modelo tradicional, desde 2015 tem sido realizada, através da "Semana de Recepção de Calouros", atividade de acolhimento, divulgação e fortalecimento institucional, organizada pelo grupo de Educação Física do Programa de Educação Tutorial (PET-Educação Física).

A Semana de Recepção de Calouros 2020 estruturou-se com base nessa perspectiva e teve por objetivo acolher os acadêmicos ingressantes de forma calorosa e informativa; integrar os discentes calouros aos veteranos; apresentar os docentes e coordenador do curso, projetos, programas e estrutura curricular da formação; informar os ingressantes sobre as propostas do grupo PET-Educação Física e convidá-los a participar; informar sobre as possibilidades de vivências universitárias.

Diante ao exposto, o presente manuscrito tem por objetivo relatar e descrever as atividades desenvolvidas na "Semana de Recepção de Calouros" dos acadêmicos do curso de Educação Física da Universidade Federal de Mato Grosso do Sul. Especificamente, objetiva apresentar as ações desenvolvidas, os resultados alcançados, avaliações realizadas posteriormente sua execução e sugestões de adequações para edições futuras.

\section{Metodologia}

O manuscrito consiste em relato de experiência, pautado na pesquisa participante, do tipo teórico-prático (Demo, 2012), referente a "Semana de Recepção de Calouros" do curso de Educação Física em 2020.

A ação consiste em ações distribuídas na primeira semana de aula da Universidade Federal de Mato Grosso do Sul (UFMS), destinada aos ingressantes no curso de Educação Física da instituição. Foi realizada no período de 17 a 21 de fevereiro de 2020 e organizada pelo grupo PET-Educação Física, com proposta aprovada pelo Colegiado do Curso.

A estrutura da semana envolveu 7 atividades ao longo de cinco dias (interação dos ingressantes e veteranos; palestra com o tema "Formação e atuação profissional"; atividades institucionais organizadas pela Pró-reitoria de Assistência Estudantil; apresentação dos professores do curso, bem como suas atividades, projetos e grupos de estudos; apresentação dos principais programas ligados aos cursos de licenciatura e bacharelado; jogos entre calouros e veteranos e o "Trote Solidário" para a arrecadação de alimentos, roupas e sapatos a serem doados às pessoas em situação de vulnerabilidade.

Parcerias foram formalizadas com a Coordenação, Centro Acadêmico de Educação Física (CAEF) e Associação Atlética Acadêmica do curso de Educação Física (AAAEF). A comissão responsável pela organização foi composta por 3 membros do PET-Educação Física, responsáveis pelo contato com os representantes da Coordenação de curso, AAAEF, CAEF; 1 encarregado de criar as artes para divulgação, 2 para o planejamento das atividades junto a AAAEF e 2 pela organização das apresentações dos docentes. A incorporação das associações atléticas e centro acadêmico nas ações de recepção de calouros também tem sido recorrida em outras Instituições de Ensino Superior do país, como a Universidade Federal de São Paulo (UNIFESP) (Noto, et. al., 2021), assim como o envolvimento da Coordenação de Curso, como no IFGoiano (Lima, et al., 2014).

A programação institucional consistiu na apresentação dos cursos da Faculdade de Educação e alguns serviços ofertados pela UFMS (Identidade Estudantil; Passe do Estudante; Restaurante Universitário - RU) e auxílios da Assistência Estudantil (Creche, Emergencial, Moradia e Permanência; Apoio Educacional ao Estudante com Deficiência).

O cronograma foi organizado conforme Quadro 1 e repassado aos professores por comunicado oficial da coordenação, como também utilizado na divulgação nas mídias sociais oficiais (WhatsApp, Facebook e Instagram) do grupo PET-Educação Física. 
Quadro 1. Cronograma Final da Semana de Recepção de Calouros 2020

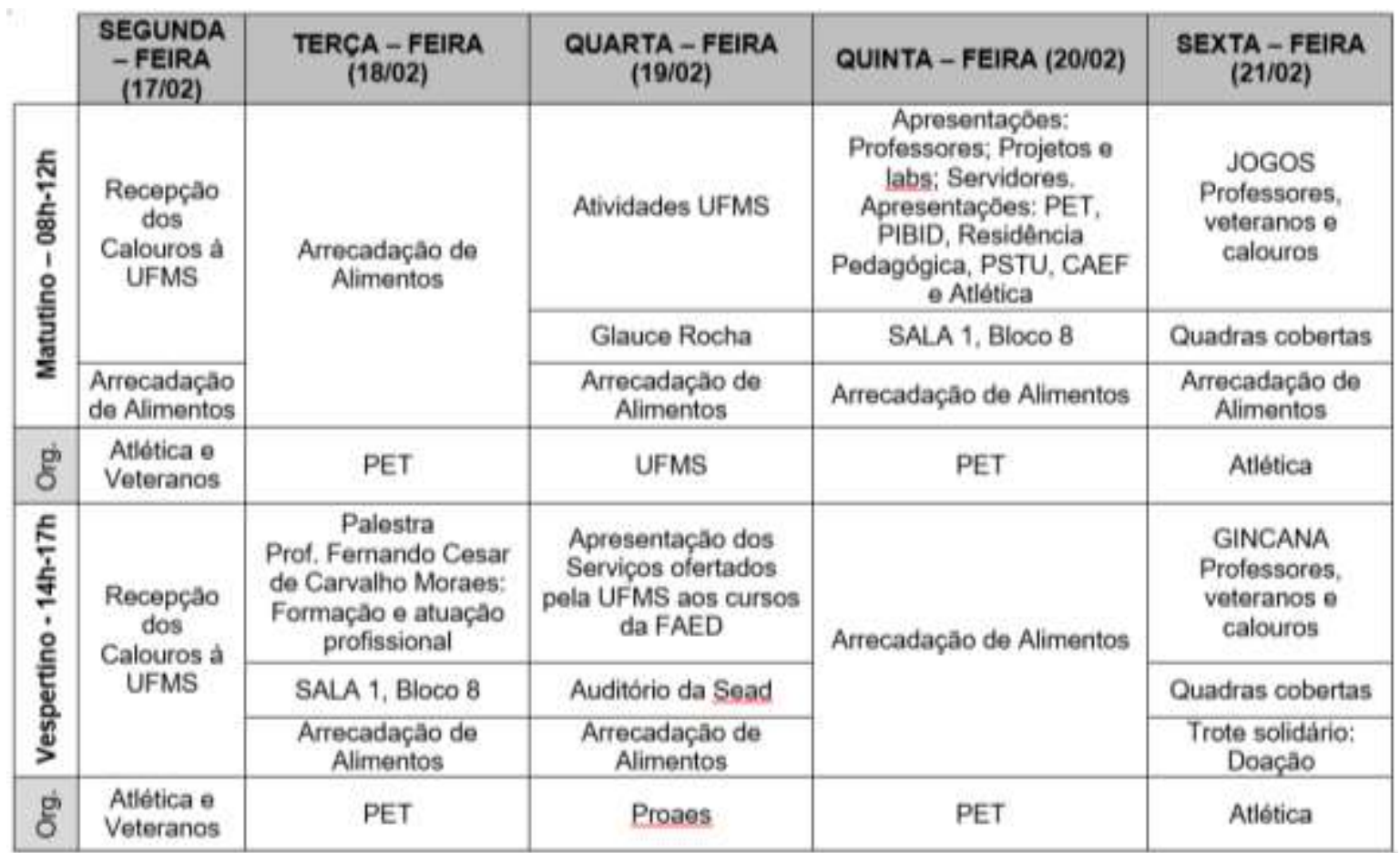

Fonte: Autores.

A estrutura da programação, composta por palestras,

No quadro acima observa-se a composição do cronograma por atividades solidárias (arrecadação de alimentos e roupas), formativa acadêmica-científica (palestra), informacional (matriz curricular do curso e programas desenvolvidos por docentes) e lúdicas integrativas (torneio de futsal, gincana e práticas esportivas recreacionais).

\section{Resultados e Discussão (Relato da Experiência)}

A semana se iniciou por intermédio da organização da composição da AAAEF, representada pelo Presidente e dois acadêmicos associados. Cada ingressante apresentou-se (nome, idade, curso - bacharelado ou licenciatura) e informou os esportes que praticavam. Posteriormente, as informações sobre o "Trote Solidário", os canais informações sobre cada ação específica e as demais atividades.

A participação da Atlética na dinâmica do primeiro dia, assim como nas atividades de integração ocorridas no último dia da semana, caracteriza-se como importante parceria no sentido de favorecer o estabelecimento de boas relações entre ingressantes e a comunidade acadêmica. Como ressaltado por Pereira e Silva (2019, p. 132), por meio de suas ações as atléticas prezam, para além do desenvolvimento e representação esportiva, buscam "[...] a integração de toda a comunidade acadêmica (alunos, professores, funcionários) através de eventos sociais e culturais", o que corrobora com os objetivos das ações desenvolvidas.

A palestra sobre formação e atuação profissional do professor de Educação Física, foi ministrada pelo segundo professor mais antigo do curso e contou com a presença de 34 acadêmicos do primeiro semestre. O ministrante abordou os campos de atuação desde a época em que era conhecida como Ginástica até a atualidade, com o reconhecimento como Educação Física e a expansão das suas Práticas Corporais, conhecimentos historicamente produzidos e transmitidos pelos homens e mulheres. Pontuou as competências e área de atuação que cada formação habilita. Ainda apresentou elementos que compõe cada uma das formações, contemplando o seu início com a Licenciatura Plena até chegar nos dispositivos legais que a 
desmembraram em duas modalidades (Licenciatura e Bacharelado). Destacou a estrutura curricular de cada formação, eixos e carga horária.

O conhecimento histórico sobre a Educação Física contribui para a compreensão da sociedade e de suas diferenciações além de estabelecer diálogo com outros campos (Melo, 1997). A distribuição de carga horária na matriz curricular de acordo com a área de conhecimento, comparando cursos de formação em Bacharelado e Licenciatura em Educação Física, apresentam características próprias e distintas (Pizani \& Barbosa, 2014). A resolução MEC/CNE n 6, de 18 de dezembro de 2018 institui as diretrizes comuns para os cursos de Educação Física e específica os aspectos da formação do licenciado e do bacharel, afirmando que a formação do licenciado será

[...] humanista, técnica, crítica, reflexiva e ética qualificadora da intervenção profissional fundamentada no rigor científico, na reflexão filosófica e na conduta ética no magistério, ou seja, na docência do componente curricular Educação Física, tendo como referência a legislação própria do Conselho Nacional de Educação para a área. (Brasil, 2019, p. 4).

Quando a formação do bacharel, a resolução afirma que deverá

[...] ser concebida, planejada, operacionalizada e avaliada, qualificando-o para a intervenção profissional em treinamento esportivo, orientação de atividades físicas, preparação física, recreação, lazer, cultura em atividades físicas, avaliação física, postural e funcional, gestão relacionada com a área de Educação Física, além de outros campos relacionados às práticas de atividades físicas, recreativas e esportivas. (Brasil, 2019, p. 5).

A palestra configurou-se como ação importante para a compreensão a respeito do percurso histórico da Educação Física e das possibilidades de sua formação (licenciatura e bacharelado), pois as diferenças entre ambas podem parecer mínimas, mas dispõem de especificidades que distinguem o campo de atuação profissional. Conforme Lima et al., (2014), esse tipo de atividade contribui para um melhor conhecimento sobre a área de atuação profissional na visão dos calouros.

A apresentação dos professores e servidores ocorreu em dois dias, com participação de onze docentes, os quais verbalizaram sua formação, projetos e linha de pesquisa. Posteriormente, seguiu-se com as apresentações dos programas e projetos (PET, Programa de Iniciação à Docência, Programa Segundo Tempo Universitário) e entidades acadêmicas (AAAEF e CAEF), os quais disponibilizaram informações sobre a estrutura, ações que realizam, como participar e entre outras. A importância dessa atividade se dá no sentido de que, por vezes, existe o desconhecimento, por grande parte dos ingressantes, a respeito das oportunidades existentes dentro da IES. Lima et al. (2014) apontam que 64\% dos calouros não tinham conhecimento sobre o PET e 15\% não conheciam nada sobre as bolsas oferecidas pela instituição.

Conhecer as possibilidades que o curso oferece é garantir que o ingressante vislumbre quais caminhos estão disponíveis e onde ele pode encaixar-se a partir do início do curso, o que proporciona crescimento intelectual e pessoal (Teixeira, et al., 2008).

Como última atividade da Semana, realizou-se, no Ginásio coberto da UFMS, o torneio de futsal entre professores, veteranos e calouros (matutino) e gincana, com a finalidade de integrar a comunidade acadêmica (vespertino). Participaram 4 equipes mistas (ingressantes de Bacharel e Licenciatura; atlética com um professor do curso; veteranos de 2019 com outro professor do curso e veteranos 2018.

O formato de disputa por grupo único (todos contra todos), com os dois times com maior pontuação classificados para final. A competição envolveu os trinta e nove competidores (diretamente ligados com a ação) e vários espectadores.

A gincana contou com a participação de 4 equipes (ingressantes do bacharelado, ingressantes da licenciatura 1, ingressantes da licenciatura 2 e veteranos), cada equipe composta por 8 integrantes. Três provas, dois circuitos e um Quiz sobre o curso figuraram como provas. 
O primeiro circuito foi composto por prova de adivinhação de objetos com o participante vendado; transferência de duas bolinhas de papel com uso do sopro de uma marca até outra; estourar cinco balões se abraçando; atravessar a quadra de vôlei, com o auxílio de dois tatames, sem encostar no chão.

A segunda prova consistiu em jogos utilizados em festas open bar: acertar o bambolê no companheiro de equipe; acertar a bolinha de tênis de mesa dentro do copo, quicando-a na mesa; 10 giros em um cone e chutar a bola de futsal e acertar o gol, repetindo a execução até acertar. Após cumprir as provas, o integrante deveria retornar a fila, tocar a mão do parceiro, para que ele desse sequência a prova, reproduzindo as mesmas tarefas do parceiro.

A gincana teve adesão menor ao esperado, visto que envolveu diretamente trinta e dois participantes e obteve menor número de espectadores, quando comparado ao futsal, realizado no matutino. Entretanto, envolveu quantidade maior de calouros. A menor participação pode ser explicada pelo envolvimento dos alunos na quadra ao lado, onde discentes estavam praticando vôlei e basquete, o que dispersou a atenção da gincana. Apesar da não participação direta, organizar um dia para práticas, fez com que, voluntariamente, várias pessoas se articulassem para praticar outras atividades e isso influenciou indiretamente no objetivo principal da integração dos acadêmicos do curso de Educação Física.

O momento do ingresso no ensino superior é um processo que repercute psicologicamente nos jovens estudantes, essa entrada no mundo universitário é uma experiência que pode ser potencialmente estressora e que traz uma série de mudanças pessoais a esses estudantes (Teixeira, et al., 2008). Nesse sentido, as atividades esportivas e a gincana organizada para esse momento de recepção dos ingressantes, que caracterizam um lazer físico-esportivo ligado ao curso de educação física, tiveram o intuito de possibilitar a socialização dos calouros com a comunidade acadêmica presente.

A respeito do trote solidário, a atividade foi desenvolvida em parceria com a instituição de caridade Life Brasil. Consistiu na arrecadação de roupas e alimentos para doação a uma comunidade em situação de vulnerabilidade. Foi estabelecida a meta de arrecadação de 40 kits, com 40kg de arroz, $40 \mathrm{~kg}$ de feijão, 40 frascos de óleo e 40 pacotes de macarrão. Foram recebidas doações feitas por acadêmicos e professores, totalizando $15 \mathrm{~kg}$ de arroz, $14 \mathrm{~kg}$ de feijão, 2 litros de óleo, $9 \mathrm{~kg}$ de macarrão, $2 \mathrm{~kg}$ de trigo, além de 2 sacos de 100L com roupas diversas e 1 saco de 100L com calçados, tênis e chinelos. Ainda, foram arrecadados $\mathrm{R} \$ 68,85$ (sessenta e oito reais e oitenta e cinco centavos), utilizados para a compra de $21 \mathrm{~kg}$ de alimentos, os quais foram repassados a comunidade carente do Bairro Jardim Carioca.

$\mathrm{Na}$ avaliação do evento, a comissão organizadora, identificou elementos a serem melhorados no cronograma na próxima edição do evento. Este item foi considerado como complexa, pois teve que ser reformulado várias vezes para suprir dificuldades impostas pelas demandas que surgiam, como alinhamento da proposta micro (Semana de Recepção de Calouros do Curso de Educação Física, organizada pelo PET Educação Física) e macro (Recepção de calouros da UFMS, organizada pela Pró-reitoria de Assuntos Estudantis).

Quanto ao espaço, evidenciou-se problemas de disponibilidade, o que limitou a ação a aconteceu na Sala 1 - Bloco 8. O diálogo com a Coordenação do Curso foi sinalizado como positiva por dois petianos, que acreditam que isso agregou significativamente ao processo de construção da ação. Quanto a unificação das turmas e a concentração da apresentação dos professores em um turno e em dois dias, ambas foram consideradas positivamente por todos os integrantes do grupo.

A seleção do palestrante também foi pontuada como elemento dificultador, vez que, dos seis nomes indicados, apenas um aceitou. Entretanto, sua participação foi avaliada como boa, com verbalização que abrangeu as duas habilitações em Educação Física (Licenciatura e Bacharelado) e foi significativa para orientação dos ingressantes no início do processo de ensino-aprendizagem dos cursos. Em relação a participação dos petianos nessa atividade, um dos integrantes sinalizou que no cerimonial de apresentação do professor, em alguns momentos, o tom da apresentação se manteve informal, com presença de gírias na fala dos petianos que estavam à frente da ação, o que não é pertinente na apresentação de um projeto, o que exige ajustes para próximas edições. 
A gincana foi bem avaliada pelos organizadores. Observaram a ação como muito boa. Porém, um fator limitador apontado foi a segunda prova, que se estendeu mais do que o esperado e tornou a experiência dos grupos que esperavam sua vez para participar, por vezes, monótona e entediante. Um dos petianos sinalizou que acreditava ter sido mais efetivo a troca dos turnos da dinâmica, pois o matutino recebeu mais adeptos que o vespertino. Outro ponto que destacou a respeito do torneio de futsal, gincana e práticas esportivas recreacionais foi a dinamicidade que aconteceu no dia com os diferentes jogos (futsal, voleibol, basquetebol).

No contexto geral, a ação atingiu seu objetivo, mobilizando parte do curso de Educação Física e integrou os ingressantes junto aos acadêmicos de vários semestres, fato esse que, devido ao calendário acadêmico, torna-se cada vez mais difícil de realizar. Porém, com a liberação dos alunos pelo colegiado do curso para participarem da ação, foi possível realiza-la, fazendo-se necessário cada vez mais a aproximação dos alunos com o colegiado para que mais ações como a Semana de Recepção de Calouros possam ser viabilizadas. Para as próximas edições deve-se pensar em ampliar a oferta de modalidades para que mais pessoas se envolvam diretamente.

A respeito do "Trote solidário", a arrecadação não atingiu a meta estabelecida, mas, visto o período total com as prorrogações já realizadas, optou-se por encerrar as doações. Apesar do baixo volume de alimentos arrecadados, considerou-se a ação positiva, vez que contribuiu com a comunidade a qual foram doadas as arrecadações. No que se refere a baixa quantidade de produtos arrecadados, considerou-se como fatores influenciadores a baixa adesão do público acadêmico em ações de doação, mesmo com a boa divulgação realizada, o público não se mobilizou. Neste sentido, para as próximas ações deve-se considerar ampliar o número de parcerias, entendê-las além do âmbito do curso de Educação Física, como também diversificar as formas de coletar e receber doações.

A respeito da adesão dos calouros e veteranos, um dos petianos avaliou como baixa, tanto por parte dos calouros quanto pelos veteranos. É possível pontuar a respeito do número absoluto de acadêmicos envolvidos e presentes nas atividades, principalmente se considerado a lista do dia 21 de fevereiro e o aferido pelos petianos no dia durante as atividades. O público presente nas ações durante a semana foi mensurado por meio das listas de presença, para veteranos e calouros, que foram passadas em cada ação. A frequência da participação de nas atividades da Semana de Recepção dos Calouros da Educação Física 2020 calouros - 29 (17/02), 34 (18/02 e 20/02) e 19 (21/02) e veteranos 41 (17/02), 27 (18/02), 7 (20/02) e 16 (21/02).

Santos et al. (2018) e Pinto et al. (2020) relataram que a participação nas atividades é inferior ao total de ingressantes, entretanto, quem participou das atividades relatou satisfação e pontos positivos em relação a recepção e o estreitamento das relações do estudante com IES, veteranos, docentes e servidores.

Neste sentido, em que pese o aumento a participação dos discentes veteranos e ingressantes na acolhida no início do semestre ser necessária e de relevância para maior alcance dos seus efeitos, deve-se considerar os aspectos positivos de sua execução e as possíveis contribuições que eventos como esses trouxeram aos envolvidos.

\section{Conclusão}

Conclui-se que a ação possibilitou o acolhimento dos acadêmicos ingressantes no curso foram de modo informativo e que promoveu a socialização por meio das atividades desenvolvidas. Ainda, fomentou a integração entre ingressantes, veteranos, professores e servidores administrativos; acesso a informação sobre as propostas do grupo PET-Educação Física, Programa de Iniciação à Docência, Programa Segundo Tempo Universitário e atuação da AAAEF e CAEF, assim como estrutura curricular do curso e projetos de extensão, ensino e pesquisa desenvolvidos pelos docentes.

Entretanto, para as próximas edições, torna-se importante que ajustes sejam realizados de modo a mitigar os aspetos identificados como negativos no desenvolvimento da ação, em especial, criar condições para que haja maior participação dos ingressantes e veteranos e ampliar a arrecadação de donativos. 
Por fim, vislumbra-se outras possibilidades de auxílio a integração dos discentes no curso de Educação Física por meio de acompanhamento permanente com atividades de integração e acolhimento, podendo ser citada como experiências futuras, a mentoria de acolhimento.

\section{Apoio}

O presente artigo foi realizado com apoio da Coordenação de Aperfeiçoamento de Pessoal de Nível Superior - Brasil (CAPES) - Código de Financiamento 001; Programa de Pós-graduação em Saúde e Desenvolvimento no Centro Oeste/Universidade Federal de Mato Grosso do Sul; Ministério de Educação por meio do fomento de bolsas no Programa de Educação Tutorial aos dois autores do artigo; Á Universidade Federal de Mato Grosso do Sul pelo financiamento do pagamento de taxa de publicação.

\section{Referências}

Akerman, M., Scalisa, F., \& Akerman, J. (2015). Para enfrentar os trotes e violências nas universidades: o que falta? Interface, 19(54), 421-425. doi.org/10.1590/1807-57622015.0426

Barros, A. S. M., Ramos, L. V. R., \& Dolabela, M. F. (2021). Atividades recreativas entre estudantes de farmácia: relato de experiência do Programa de Educação Tutorial. Brazilian Journal of Development, 7(3), 27212-27220. doi.org/10.34117/bjdv7n3-432

Bellodi, P. L. (2004). O Programa Tutores e a Integração dos Calouros na FMUSP. Revista Brasileira de Educação Médica, 28(3), 204-214 doi.org/10.1590/1981-5271v28.3-027.

Costa, R. A., Silva, R. M., Moreira, N., Ferreira, L. P., \& Dominhues, L. A. da S. (2017). Recepção cidadã: uma experiência de construção de relações humanizadas visando à permanência e êxito estudantil no IFTM Campus Uberlândia. In Martins, A. P., Ribeiro, E. A., Silveira, E. R., Lima, G. G., Andrade, L. B., Rezende, L. A., \& Guimarães, T. M. S. (Org), Processos e práticas de ensino no IFTM: o acesso, a permanência e o êxito dos estudantes (pp. 79-92). Uberaba: Instituto Federal do Triangulo Mineiro. http://periodicos.iftm.edu.br/index.php/livrosproen/article/view/211/272

Crivello Junior, O., \& Bastos Filho, H. T. (2016). A semana de Recepção aos Calouros da Universidade de São Paulo. Revista de Graduação USP, 1 (1), 107114. http://gradmais.usp.br/vol-1-n-1-jul-2016/

Demo, P. (2012). Metodologia científica em ciências sociais. (3a ed.), Atlas.

Estanque, E. (2017). A práxis do trote: breve etnografia histórica dos rituais estudantis de Coimbra. Sociologia \& Antropologia, 7 (2), 429-458. 10.1590/2238$38752017 \mathrm{v} 725$

Instituto Brasileiro de Geografia e Estatística (IBGE). (2019). Cidades. https://cidades.ibge.gov.br/

Kaji, A. K., Gazzi, B. C., Schimitd, B., Silva, M. J., \& Zöllner, M. S. A. C. (2021). Desenvolvimento de um programa de mentoria por pares estudantis: um relato de experiência. Revista Brasileira de Educação Médica, 45 (Supl.), e107. doi.org/10.1590/1981-5271v45.supl.1-20210117

Lima, G. M, Alves, T. A., Dias, M. A., Estrela, D. C., Lemes, C. G. C., Nunes, R., \& Castro, A. L. S. (2014). Recepção "Calourosa”: conhecimentos, expectativas e opiniões de ingressantes do curso de Licenciatura em Ciências Biológicas. Holos, 30(1), 282-289. doi.org/10.15628/holos.2014.1323

Lopes, B. C., Morais, A. P. M., Ferreira, R. L., Silva, F. N., \& Santos, G. M. R. (2020). Recepção dos calouros do curso engenharia de pesca da UFERSA. Brazilian Journal of Animal and Environmental Research, 3(3), 1380-1387. 10.34188/bjaerv3n3-055

Melo, V. A. (1997). Porque devemos estudar História da Educação Física nos cursos de graduação? Motriz, 2(1), 56-61. 10.5016/6501

Ministério da Educação. (2019). Resolução n ${ }^{\circ}$ 6, de 18 de dezembro de 2018. Institui Diretrizes Curriculares Nacionais dos Cursos de Graduação em Educação Física e dá outras providências. Diário Oficial da União, 1, p. 48. https://www.in.gov.br/materia/-/asset_publisher/Kujrw0TZC2Mb/content/id/55877795

Noto, J. R. S., Avancine, M. A. T. O., Martins, M. C. F. N., \& Zimmermann, V. B. (2021). Atenção à saúde mental do estudante de medicina. Revista Brasileira de Educação Médica, 25(1), 71-75. doi.org/10.1590/1981-5271v25.1-010

Pereira, B. de A., \& Silva, L. P. (2019). Políticas de esporte e lazer nas universidades federais de minas gerais: um olhar sobre as associações atléticas acadêmicas. Licere, 22(4), 95-136. 10.35699/1981-3171.2019.16263

Pinto, D., Chagags, E., Costa, G., Nunes, K., Anchieta, R., Rocha, S. \& Rivero, L. (2020). De veteranos para novatos: avaliação das atividades de recepção aos calouros organizadas pelo grupo PETComp. Anais Workshop sobre Educação em Computação (WEI), Cuiabá, 28. (pp. 61-65). Porto Alegre: Sociedade Brasileira de Computação. Retrieved from https://sol.sbc.org.br/index.php/wei/article/view/11130

Rios, I. C., Santos, C. D. V., Fernandes, E. M. O., Pacheco, M. K. O., Fernandes, M. T. A., \& Vital Junior, P. F. (2021). Mentoria de acolhimento para alunos ingressantes no curso de medicina. Revista Brasileira de Educação Médica, 45(Supl.), e111. doi.org/10.1590/1981-5271v45.supl.1-20210127

Santos, M. S., Chaves, A. R. F., Ferreira, R. da S. A., Moreira, S. F. da C., Souza, M. R., \& Borges, C. J. (2018). Acolher mais: recepção dos calouros do curso de graduação em enfermagem. Itinerarius Reflectionis, 14(4), 1-12. 10.5216/rir.v14i4.55004 
Research, Society and Development, v. 10, n. 9, e11110917519, 2021

(CC BY 4.0) | ISSN 2525-3409 | DOI: http://dx.doi.org/10.33448/rsd-v10i9.17519

Teixeira, M. A. P., Dias, A. C. G., Wottrich, S. H., \& Oliveira, A. M. (2008). Adaptação à universidade em jovens calouros. Revista Semestral da Associação Brasileira de Psicologia Escolar e Educacional (ABRAPEE), 12(1), 185-202. 10.1590/S1413-85572008000100013

Zuin, A. A. S. (2011). O trote universitário como violência espetacular. Educação e Realidade, 36(2), 587-604. https://seer.ufrgs.br/educacaoerealid ade/article/view/13132/12929 